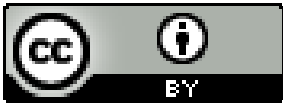

\title{
A INSERÇÃO DA MULHER NEGRA NA EDUCAÇÃO DE JOVENS E ADULTOS - EJA
}

\author{
Izanete Marques Souza ${ }^{1}$ \\ Cosmerina de Souza de Carvalho ${ }^{2}$
}

RESUMO: Esse estudo tem por objetivo debater a inserção da mulher negra na Educação de Jovens e Adultos - EJA. Para tanto, realizou-se uma pesquisa de revisão de literatura e análise documental com duas turmas do tempo formativo II, eixo V, sendo a primeira composta por vinte estudantes e a outra com vinte e oito. Nas duas turmas os discentes tinham entre dezoito e sessenta anos e estavam alocadas numa escola no município de Ilhéus/BA. A relevância da pesquisa se encontra no fato de pensar a inserção de mulheres negras na Educação de Jovens e Adultos abordando questões históricas, sociais e culturais, bem como na tentativa de entender a escola como um espaço de acolhimento das diversidades. Partindo desta realidade analisou-se, ainda, os dados do Censo Escolar 2018 dessa escola buscando respostas para as seguintes questões: Qual relação quantitativa para a entrada, permanência e êxito de homens e mulheres da EJA? Estes estudantes são em sua maioria de que cor? A partir da análise dos dados de entrada, permanência e êxito dos estudantes observou-se um alto índice de evasão dos discentes, tanto dos homens como das mulheres, porém durante a investigação foi possível perceber que a maioria das discentes que evadiram possuíam um vínculo empregatício e tinham filhos o que indica um acúmulo de funções que apesar de levá-las a evasão ainda faz com representem a maioria do público da EJA no locus da pesquisa.

Palavras-Chave: Mulher negra. Educação. EJA.

THE INSERTION OF BLACK WOMAN IN YOUTH AND ADULT EDUCATION - EJA

\footnotetext{
${ }^{1}$ Mestre em Educação e Diversidade pela UNEB - Universidade do Estado da Bahia, é professora no IF BAIANO - Instituto Federal de Educação, Ciência e Tecnologia Baiano onde presidiu a comissão de implantação do NEABI - Núcleo de Estudos Afro-brasileiros e Indígenas. Foi Coordenadora do NEABI Geral de 2014 a 2019 e é pesquisadora no NEABI, na linha de pesquisa Produção de Conhecimento, etnicidade e formação profissional. Líder do GEPEDET - Grupo de Pesquisa em Educação, Diversidade, Linguagens e Tecnologia com a linha de pesquisa Educação, Cultura e Diversidade. E-mail: izanete.souza@ifbaiano.edu.br

${ }^{2}$ É especialista em Leitura e Produção Textual Aplicadas à Educação de Jovens e Adultos, pelo Instituto Federal de Educação, Ciência e Tecnologia Baiano - IF BAIANO. Membro egresso como estudante do GEPEDET - Grupo de Pesquisa em Educação, Diversidade, Linguagens e Tecnologias, sempre estudou em escolas públicas e ingressou no ensino superior por meio das cotas para negros. Dedica este artigo à sua mãe, a qual estudou na Educação de Jovens e Adultos - EJA e que sempre apoiou a filha no seu processo de escolarização. Hoje é professora da educação básica na rede pública municipal.
}

Revista da ABPN・v. 12, n. $31 \cdot \operatorname{dez} 2019$ - fev 2020, p. 267-291 
Abstract: This study aims to discuss the inclusion of black women in Youth and Adult Education - EJA. To this end, a literature review and documentary analysis research was conducted with two classes of formative time II, axis V, the first consisting of twenty students and the other with twenty-eight. In both classes the students were between eighteen and sixty years old and were allocated to a school in the municipality of Ilhéus / BA. The relevance of the research lies in the fact that thinking about the inclusion of black women in Youth and Adult Education, addressing historical, social and cultural issues, as well as trying to understand the school as a space for welcoming diversity. Based on this reality, we also analyzed data from the 2018 School Census of this school seeking answers to the following questions: What quantitative relationship for the entry, permanence and success of men and women of the EJA? Which students are mostly what color? From the analysis of the data of entry, permanence and success of the students it was observed a high dropout rate of the students, both men and women, but during the investigation it was possible to realize that the majority of the students who dropped out had a job bond and they had children, which indicates an accumulation of functions that, despite leading them to evasion, still represent the majority of the EJA public at the research locus.

Keywords: Black women. Education. EJA.

\section{LA INSERCIÓN DE MUJER NEGRA EN EDUCACIÓN JUVENIL Y ADULTA -} EJA

Resumen: Este estudio tiene como objetivo discutir la inclusión de las mujeres negras en la educación de jóvenes y adultos - EJA. Con este fin, se llevó a cabo una revisión de la literatura y una investigación de análisis documental con dos clases de tiempo formativo II, eje V, el primero compuesto por veinte estudiantes y el otro con veintiocho. En ambas clases, los estudiantes tenían entre dieciocho y sesenta años y fueron asignados a una escuela en el municipio de Ilhéus / BA. La relevancia de la investigación radica en el hecho de pensar en la inclusión de las mujeres negras en la educación de jóvenes y adultos, abordar problemas históricos, sociales y culturales, así como tratar de entender la escuela como un espacio para acoger la diversidad. En base a esta realidad, también analizamos datos del Censo Escolar 2018 de esta escuela buscando respuestas a las siguientes preguntas: ¿Qué relación cuantitativa para la entrada, permanencia y éxito de hombres y mujeres de la EJA? Qué estudiantes son principalmente de qué color? Del análisis de los datos de ingreso, permanencia y éxito de los estudiantes se observó una alta tasa de deserción de los estudiantes, tanto hombres como mujeres, pero durante la investigación fue posible darse cuenta de que la mayoría de los estudiantes que abandonaron tenían un vínculo laboral y tuvieron hijos, lo que indica una acumulación de funciones que, a pesar de llevarlos a la evasión, todavía representan a la mayoría del público de EJA en el lugar de investigación.

Palabras clave: Mujer negra. Educación. EJA.

L'INSERTION DE LA FEMME NOIRE DANS L'ÉDUCATION DES JEUNES ET DES ADULTES - EJA

Résumé: Cette étude vise à discuter de l'insertion des femmes noires dans le Éducation des jeunes et des adultes - EJA. Pour cela, une recherche de revue de la littérature et

Revista da ABPN • v. 12, n. $31 \cdot \operatorname{dez} 2019$ - fev 2020, p. 267-291 
analyse de documents avec deux groupes de temps formative II, axe V, le premier composé de vingt étudiants et le un autre avec vingt-huit. Dans les deux classes, les étudiants avaient entre dix-huit et soixante ans et ont été attribués à une école de la commune d'Ilhéus / BA. Un la pertinence de la recherche réside dans le fait de penser à l'insertion des femmes dans l'éducation des jeunes et des adultes abordant des questions historiques, facteurs sociaux et culturels, ainsi que pour tenter de comprendre l'école comme un espace pour accueillir les diversités. Partir de cette réalité les données du recensement scolaire 2018 de l'école étaient également réponses aux questions suivantes: Quelle relation quantitative avec entrée, permanence et succès des hommes et des femmes de l'EJA? Ces étudiants sont-ils principalement de quelle couleur? De l'analyse des données d'entrée, permanence et réussite des élèves, un taux d'abandon élevé étudiants, hommes et femmes, mais au cours de l'enquête on a pu constater que la majorité des élèves qui avaient abandonné avaient um emploi et a eu des enfants, ce qui indique une accumulation de fonctions qui en dépit de les amener à l'évasion, il représente toujours la majorité du public d'EJA sur le site de recherche.

Mots-clés: femme noire; Éducation; EJA.

\section{INTRODUÇÃO}

A Educação de Jovens e Adultos (EJA) é uma modalidade de ensino que ainda carece de pesquisas para serem utilizadas como norteadoras na prática pedagógica, de modo que venha a melhor atender a este público que é bem diversificado. Contudo, essa carência abrange a educação de forma geral, causando certo distanciamento entre a pesquisa acadêmica e a prática educacional.

Dentre as diversas demandas sociais é relevante buscar discutir a permanência e o êxito de homens e mulheres na EJA bem como a etnia destes estudantes. Essas discussões podem gerar produções científicas e levantamento de problemáticas acerca da inserção e da aprendizagem no processo de ensino na EJA. Por tratar-se de sujeitos que não concluíram os estudos na idade considerada certa e que em outro período têm a oportunidade de ingressar no sistema de ensino oficial do estado novamente, é um desafio para a escola oferecer um ensino voltado para o público em questão, possibilitando o fortalecimento de atuação destas pessoas na sociedade que de alguma maneira tiveram seus direitos negados ao serem impedidas de continuar os estudos.

Assim, considera-se potencial estudante da EJA todos os brasileiros e brasileiras com 15 anos de idade ou mais que não completaram o ensino fundamental e com dezoito ou mais que não completaram o ensino médio. Dessa forma pode-se afirmar que o ambiente escolar nessa modalidade é bem diverso, uma vez que envolve estudantes 
com realidades e idades diferenciadas na sala de aula, fato que possibilita uma troca de experiências e saberes que refletem na aprendizagem dos educandos.

Os dados do Instituto Nacional de Estudos e Pesquisas Educacionais Anísio Teixeira - INEP, censo escolar de 2016, apontam uma parcela expressiva de jovens matriculada na EJA, sugerindo que essa modalidade de ensino recebe alunos provenientes do ensino regular os quais são, em número significativo, estudantes com histórico de retenção buscando meios para conclusão dos estudos.

A partir da análise dos dados de entrada, permanência e êxito dos 48 estudantes da EJA, tempo formativo II, eixo V, de uma escola do município de Ilhéus que atende a 672 estudantes, sendo 120 na Educação Infantil, 480 do $1^{\circ}$ ao $5^{\circ}$ ano do Ensino Fundamental e apenas 72 da EJA noturna (Censo Escolar 2018), observou-se um alto índice de evasão dos discentes, tanto dos homens como das mulheres, porém durante a investigação foi possível perceber que a maioria era do sexo feminino e que as discentes que evadiram possuíam um vínculo empregatício e tinham filhos. Esse fato pode ser consequência do acúmulo de funções que as mulheres possuem o que não impediu que a maioria do público da EJA nesta escola fosse do sexo feminino.

Partindo desta realidade analisou-se os dados do Censo Escolar 2018 dessa escola, referentes a duas turmas da EJA buscando respostas para as seguintes questões: Qual a relação quantitativa para a entrada, permanência e êxito de homens e mulheres? Estes estudantes são em sua maioria de que cor?

Para responder a estas questões considerou-se negros e negras os(as) estudantes que se autodeclararam pretos (as) ou pardos (as) no momento da matrícula cuja informação constava na ficha de matrícula que foi um dos documentos utilizados para a coleta dos dados no que concerne a cor e demais informações que estão presentes na pesquisa. Os demais documentos, além dos dados do censo escolar, foram: as fichas de frequências das turmas de educação infantil, fundamental e EJA utilizadas para contabilizar a população de estudantes da escola, tendo em vista que esta instituição atende aos três níveis de ensino; as fichas dos componentes curriculares da EJA informando as disciplinas que fazem parte da matriz curricular que possui seis componentes: Língua Portuguesa, Matemática, História, Geografia, Ciências, Artes e Educação para o Trabalho.

Analisou-se ainda a tabela com o horário escolar vigente no ano letivo de 2018 além das tabelas de distribuição da carga horária, onde foi possível verificar o número 
de horas-aula dedicadas à sala de aula, uma vez que a carga horária docente ${ }^{3}$ inclui o tempo de planejamento; as fichas de cadastro dos funcionários informando a formação específica de cada professor, inclusive dos que atuam na EJA; as fichas de matrícula que foram elementos importantes para a elaboração dos gráficos com informações a respeito do sexo e da cor autodeclarada, bem como a comparação da idade, estado civil e profissão. Também foram analisados e comparados por meio dos gráficos os mapas de resultados finais com o número de discentes matriculados, evadidos (que deixaram a escola sem a conclusão do eixo formativo ou sem transferência formalizada), aprovados e conservados (mantidos no mesmo eixo formativo) para o próximo ano letivo.

No tocante à formação dos educadores, apenas dois dos professores possuem a formação na área específica em que atuam: a professora de Língua Portuguesa que é formada em Letras e o professor de Ciências que é formado em Biologia, os demais são pedagogos. Quase todos os professores lecionam também no diurno, alguns pela manhã e à noite, outros à tarde e à noite, em regime de quarenta horas na mesma instituição. A supervisora pedagógica também trabalha em regime de quarenta na escola em questão. Apenas a professora de Educação para o Trabalho e Artes atua em regime de complementação de carga horária, ela leciona no período da tarde nas turmas de quarto e quinto ano do ensino fundamental na mesma escola o que implica em 20 horas no quarto ano, 14 horas no quinto ano e apenas 6 horas-aula nas duas turmas noturnas da EJA.

Nesse sentido pode-se levar em consideração a sobrecarga dos professores e a atuação em disciplinas nas quais não possuem a formação específica para tal como um elemento que implica também numa formação de qualidade para os estudantes da EJA, já que de acordo com Almeida (2004, p. 172) “a elevada carga de trabalho semanal do professor fruto da intensificação do trabalho, faz com que os docentes atuem de maneira dispersa”. Essa dispersão pode afetar a oferta do ensino na EJA de tal maneira que o estudante tenha dificuldade na aprendizagem e o professor não se sinta disposto a

\footnotetext{
3 Mesmo com o locus da pesquisa sendo integrante da rede municipal é salutar informar que de acordo com o Manual de Programação Escolar - Regras 2018 da Rede Estadual de Ensino da Bahia o professor com uma jornada de trabalho de 40 horas semanais que atua nas séries finais do Ensino Fundamental e no Ensino Médio deverá exercer 26 horas-aula de regência, 10 horas de planejamento, correção de material avaliativo e de estudo na Unidade Escolar e 04 horas-aula em espaço de escolha do docente. A carga horária de regência poderá ainda ser preenchida com horas-aula como articulador de área dentre outras funções.
} 
ensinar atendendo a particularidade do discente, devido ao cansaço por conta do intenso trabalho ao longo do dia e a necessidade de maior tempo de estudo para lecionar disciplinas para as quais não foi habilitado na graduação.

A partir do pressuposto de que a função da escola na EJA é facilitar o ingresso e a permanência dos sujeitos no mundo do trabalho, dando continuidade ao processo de escolarização, além de propiciar o desenvolvimento de habilidades para o exercício pleno da cidadania em uma sociedade capitalista percebe-se que esta distorção entre a área de formação acadêmica docente e a área de atuação em sala de aula poderá impactar na permanência desses discentes não por falta de compromisso dos profissionais, mas por falta de condições pedagógicas adequadas a esta permanência.

Outro aspecto a ser considerado, de acordo com Costa (2009, p. 17), é que "as mulheres negras ainda têm pouco acesso à escolarização e, em sua maioria, encontramse no mercado informal de trabalho, particularmente em atividades domésticas" o que implica dizer que a discriminação de gênero e cor atinge diretamente as mulheres negras na sociedade brasileira, dando continuidade a uma situação histórica que, acrescida das atividades de cuidados domésticos em suas casas, têm contribuído para ampliar os índices de evasão na EJA.

Dessa maneira, a fim de discutir a inserção da mulher negra na Educação de Jovens e Adultos realizou-se um trabalho de revisão de literatura e de análise documental de duas turmas do tempo formativo II, eixo V, sendo a primeira composta por vinte estudantes e a outra por vinte e oito. Nas duas turmas os discentes tinham entre 18 e 60 anos de idade. No tocante à relevância da pesquisa esta se encontra no fato de pensar a inserção de mulheres negras na EJA abordando questões socioculturais, comparando a presença do sexo feminino e do masculino com o índice de evasão, aprovação e retenção de modo a olhar para a escola como um espaço de acolhimento das diversidades.

Ainda em relação à metodologia, Silva et al (2009, p. 13) afirma que "a pesquisa documental é um método decisivo, porque a maior parte das fontes são quase sempre a base do trabalho de investigação e pode se caracterizar como o principal caminho de concretização da investigação". Assim, foram utilizadas apenas fontes documentais para a coleta de dados, recorrendo a fontes consideradas primárias que na concepção de Silva et al (2009) são aquelas que não receberam nenhum tratamento analítico anteriormente. Nesse sentido, os dados foram agrupados por categorias, permitindo assim, segundo 
Bardin (2010), verificar o que cada um tinha em comum com os outros de modo a possibilitar uma análise temática à luz da teoria Análise de Conteúdo.

A análise dos dados desta pesquisa demonstrou que essas mulheres que se matricularam na EJA são, em sua maioria, de baixa renda e negras, uma vez que a análise dos documentos apontou que, na turma I, todas as estudantes eram negras, 5 trabalhavam como domésticas, 3 trabalhavam como autônomas e duas apenas estudavam. Na turma II, das 16 estudantes, 14 eram negras e 2 brancas, 7 trabalhavam como domésticas, 8 registraram trabalhar em outras atividades e apenas uma, de acordo com os dados da ficha de matrícula, não trabalhava.

A partir desses dados pode-se afirmar que essas mulheres buscam a EJA enquanto um lugar específico de formação para assim enfrentar os desafios cotidianos e adquirir o reconhecimento do seu espaço na sociedade, enquanto profissional e pessoa consciente dos seus direitos para tornar-se, cada vez mais, mulheres livres e empoderadas.

\section{A MULHER NEGRA E O TRABALHO NO BRASIL}

A existência da mulher negra no contexto histórico brasileiro é marcada pela discriminação cujo início no período colonial com a escravização dos povos africanos que foram trazidos para o Brasil sob a égide de violências diversas tais como a realização de trabalhos braçais em condições sub-humanas, a separação de seus filhos no momento do parto, abusos sexuais praticados pelos senhores de engenho e pelos feitores no período escravagista e por homens com diversas funções sociais na atualidade, dentre outros tipos.

De acordo com Nascimento e Santos (2018, p. 02), "a mulher escravizada nunca foi poupada em relação a sua condição física, os trabalhos braçais realizados pelos homens na agricultura eram também realizados por esta”. Apenas a mulher branca não podia exercer trabalhos braçais, a ela era dada a obrigatoriedade de administrar o lar, executar tarefas exclusivamente domésticas e procriar. Contudo, essa realidade não pertencia à mulher escravizada.

Nesse sentido, Munanga e Gomes (2006) dizem que a mulher negra sempre sofreu uma dupla discriminação: ser mulher em uma sociedade machista, e ser negra em uma sociedade marcada pelo racismo. Essa dupla discriminação por causa do gênero e 
da raça fez dessa minoria vítima de atos racistas ao longo da história. Enquanto a mulher branca lutou para ter direito ao estudo e ocupar um lugar de prestígio profissional, a negra teve que lutar por tudo isso e para sobreviver também a tantos outros atos abusivos por parte da sociedade devido à sua condição étnica já que mesmo após a assinatura da abolição da escravatura a mulher negra continuou a sofrer abusos de diversas maneiras, a exemplo do trabalho doméstico mal remunerado, os corpos violentados e vistos como objetos de desejos por parte da burguesia, como afirma Nascimento e Santos (2018):

Este legado deixado pelo período escravagista, em relação à violência física e sexual contra a mulher se estende até os dias atuais. A cultura do estupro realizada contra as mulheres escravizadas no início do século XVI ainda é uma realidade em muitos cantos do mundo incluindo o Brasil. Ainda hoje os corpos das mulheres negras continuam sendo os mais suscetíveis a serem violentados e assassinados (NASCIMENTO e SANTOS, 2018, p. 71).

Assim, a mulher negra por muito tempo era vista apenas como um objeto utilitário para servir em relação ao trabalho braçal e à exploração sexual. Esse olhar de discriminação, infelizmente, perdura até os dias atuais, principalmente, no que se refere ao corpo negro, visto como um objeto de oferta de prazer. A mídia elitista brasileira ainda insiste em apresentar a mulher negra como a "mulata gostosa" desprovida de outros atributos. O turista estrangeiro ainda teima em potencializar a prostituição da mulher negra. As empresas ainda resistem em contratar a mulher negra baseando-se na sua competência profissional sem atrelar isso ao seu estereótipo físico.

Destarte, ainda hoje, percebe-se que as mulheres negras compoem o grupo social que menos têm acesso aos seus direitos sociais, a exemplo de educação pública de qualidade, moradia, emprego, saúde e lazer assegurados. Enfim, “acessos que lhes deem condições para ascender social e economicamente e, por consequência, reparar todas as mazelas realizadas desde a origem do processo de escravização" (NASCIMENTO e SANTOS, 2018 p. 72).

$\mathrm{Na}$ perspectiva de que os aspectos discriminatórios de gênero e raça sempre estiveram presentes na história das mulheres negras, gerando, consequentemente, desigualdade social e dificultando a inserção dessas no mundo do trabalho com profissões de prestígio, Munanga e Gomes (2006, p. 102), ratificam uma realidade muito antiga da mulher negra, que desempenhava funções domésticas - tipo de trabalho 
sempre desvalorizado econômica e socialmente - enquanto escravizada o que implica dizer que "a mulher negra tem sido aquela que cuida da casa e dos filhos de outras mulheres para que possam cumprir uma jornada de trabalho fora de casa”. Sendo assim, a conquista de um espaço privilegiado no mundo do trabalho pelas mulheres contemporâneas tem acontecido, na maioria das vezes, apenas com a mulher branca.

Deste modo, por muito tempo as mulheres lutaram para conquistar seus direitos na esfera social, intensificando-se estes movimentos na década de 1960. Porém, essas lutas eram apenas uma luta de gênero, deixando assim de favorecer a racialidade da mulher negra fato que dá sustentação a Munanga e Gomes (2006, p. 102) para afirmarem que "esse processo levou as mulheres negras a questionarem a ausência da discussão do gênero articulada com a questão racial dentro do movimento feminista e dos movimentos negros". Nas lutas dos movimentos negros não se discutiam as questões das mulheres negras, mas dos negros em geral, por isso as mulheres negras se organizaram para lutas específicas e essas manifestações acontecem até os dias atuais sob o nome de feminismo negro.

\section{A MULHER NEGRA, O PROCESSO EDUCACIONAL E A EJA}

Como anunciado anteriormente. a presença das mulheres na EJA é reflexo da falta de oportunidade destas para continuar no ensino regular e concluir a educação básica na idade certa, uma vez que, a maioria teve que evadir da escola para trabalhar e ajudar financeiramente a família, exercendo funções voltadas para as atividades domésticas, as quais exigem o mínimo ou nenhum nível de escolaridade.

Por questões históricas e sociais a maioria das mulheres que evadiu no ensino regular é negra. Mesmo após a assinatura da abolição da escravatura, em 1888, o negro continuou em uma posição de subalternidade, sem emprego e sem acesso à educação já que "a liberdade para os ex-escravizados não representou o acesso às instituições políticas e aos direitos civis e sociais" como afirma PEREIRA (2015, p. 104), de modo que saíram dos cativeiros, porém não podiam exercer os mesmos direitos que a população branca, passando a viver à margem da sociedade.

No pós-abolição, o não acesso às formas primeiras de sobrevivência que seria o trabalho, as populações negras estiveram alijadas do acesso à escola, ora sob a forma de lei proibitivas, ora sob a forma de exclusão que se efetiva por mecanismos simbólicos e explícitos em que estão colocadas diferentes formas de racismo e discriminação (NUNES, 2018 p. 124)

Revista da ABPN • v. 12, n. $31 \cdot \operatorname{dez} 2019$ - fev 2020, p. 267-291 
Ainda de acordo com Nunes (2018), para se ter acesso à escola neste período pós-abolição era necessário ser considerado cidadão, no entanto, os negros não tinham o título de cidadania o que implica dizer que "a nova situação dos negros, de escravizados para libertos, não foi aceita imediatamente pela sociedade brasileira" (MUNANGA E GOMES, 2006, p. 83) o que resultou no fato de que, nesse contexto, o Brasil foi se tornando cada vez mais desigual com os negros vivendo na linha da pobreza o que levou à formação de grupos para lutar e resistir a essa desigualdade e construir a cidadania da população negra até os dias atuais.

Nesta perspectiva de luta, o povo negro no Brasil, por muito tempo, organizou as suas escolas na informalidade, uma vez que tinham seus direitos negados, tais escolas eram decorrentes da organização em associações religiosas cujo ensino informal era efetuado por pessoas que tiveram a oportunidade de se escolarizar em terreiros ou em outras comunidades negras (NUNES, 2018). Nesse sentido destaca-se que:

\begin{abstract}
A história de luta dos negros nesses movimentos foi de fundamental importância na conquista dos direitos sociais, políticos e culturais. Eram grupos organizados e com muita resistência conseguiram o respeito político da situação. De acordo com os autores acima o Movimento Frente Negra Brasileira, o Teatro Experimental do Negro e o movimento das Mulheres Negras tinha "uma proposta que fundamentava-se em uma filosofia educacional, acreditando que o negro venceria à medida que conseguisse firmarse nos diversos níveis da ciência, das artes e da literatura" (MUNANGA e GOMES, p. 92).
\end{abstract}

A partir da afirmação acima entende-se que esses grupos lutavam para que a população negra tivesse acesso à educação e dessas lutas muitas conquistas foram efetivadas, graças a não passividade da população afrodescendente frente a discriminação no país. Deste modo, algumas políticas de ações afirmativas foram conquistadas com o objetivo de promover a igualdade de direitos entre as etnias, a exemplo do que diz o artigo $1^{\circ}$, inciso VI da lei $\mathrm{N}^{\mathrm{o}} 12.288$, de 20 de julho de 2010 que é o Estatuto da Igualdade Racial ao definir como "ações afirmativas: os programas e medidas especiais adotados pelo Estado e pela iniciativa privada para a correção das desigualdades raciais e para a promoção da igualdade de oportunidades". Essas ações são estabelecidas nas esferas sociais, políticas, educacionais e culturais.

Neste caso, dentre as ações afirmativas é válido ressaltar a finalidade de corrigir a vasta desigualdade de acesso à educação nas instituições de ensino superior com a 
implantação do sistema de cotas que vem cumprir um papel importante ao desmascarar a falácia da democracia racial no Brasil que transfere o resultado de uma política de mais de 500 anos de genocídio e descaso social. A implementação das cotas tem desmistificado e corrigido, em parte, a absurda ideia de incompetência da população negra tão disseminada ainda na sociedade nacional.

A tentativa de propagação do mito da democracia racial, certamente, tem como finalidade mascarar a ineficiência e a falta de investimentos do sistema público de ensino o qual tenta transferir essa ineficácia para os estudantes negros. Assim, a permanência das cotas é uma demanda necessária e deve estar diretamente ligada à luta pela defesa de uma educação pública inclusive nos institutos federais que, na condição de instituições de ensino superior, oferecem educação básica profissionalizante integrada ao ensino médio, gratuita e de qualidade a serviço da classe trabalhadora, pobre e secularmente colocada às margens da sociedade.

Apesar de representar um avanço em relação ao abismo de oportunidades, existente entre negros e brancos, principalmente da mulher negra, as cotas por si só não resolvem os problemas desse grupo social, que muitas vezes sequer completa a educação básica de modo que há a importância de defender um programa que leve até o fim a democratização da educação, que se choque diretamente com os interesses da burguesia e leve ao questionamento da lógica mercadológica a qual a educação está submetida.

Todavia, tais medidas legais não tendem a ser benéficas apenas para um determinado grupamento étnico. Elas mexem, sim, com possibilidades riquíssimas de partilhas, dentre elas, de um conhecimento que não é propriedade individual, mas sim patrimônio social da humanidade. As relações sociais, sabidamente, são perpassadas por relações e, entre elas, de disputa de poder; estas conquistas legais, que são também desafios para a população negra e não negra, simbolizam caminhos por onde sair de uma falsa ideia de que vivemos uma sociedade racialmente harmônica, bem como de nos depararmos frente a perspectivas de fortalecimento identitário, na medida em que passamos a conviver com uma imensidão de repertórios estéticos, teóricos, conceituais e corporais que nos levam a reconhecer o/a outro/a e a nós mesmos (NUNES, 2018, p. 127).

Existem outras ações afirmativas que favorecem a igualdade racial no Brasil, a exemplo da oferta de uma educação de jovens e adultos sintonizada com os princípios libertadores da EJA moderna. Mas isso não é o suficiente para considerar que no país existe democracia racial. 
Sobre a discrepância de oportunidades existente entre a mulher negra e a branca o artigo $1^{\circ}$, inciso III do Estatuto da Igualdade Racial (2010) conceitua a desigualdade de gênero e raça como sendo a "assimetria existente no âmbito da sociedade que acentua a distância social entre mulheres negras e os demais segmentos sociais." Dessa maneira, a mulher tem buscado usufruir o direito a igualdade de gênero previsto nas leis que representam as conquistas resultantes da luta do movimento feminista das mulheres negras e demais movimentos como o movimento negro unificado, além dos movimentos progressistas ligados aos direitos humanos assim como afirmam MUNANGA e GOMES (2006):

Sendo a mulher negra mais vulnerável à violência aos direitos humanos e por representarem quase a metade da população feminina no Brasil, qualquer estratégia de promoção da mulher deve considerar as diferenças que existem entre as mulheres, adaptando as políticas públicas às necessidades reais das mulheres brancas, negras e indígenas, para que essa metade da população feminina, negra e indígena chegue junto com a mulher branca ao poder (MUNANGA e GOMES, 2006, p. 103).

A mulher negra que faz parte de um grupo com tantos direitos negados e uma história de luta e resistência, vítima de uma sociedade colonizadora, tem buscado um lugar justo no contexto social, procurando a educação enquanto um meio de emancipação crítica o que condiz com a afirmação de Ribeiro et al (2015), de que a EJA é considerada uma política de ação afirmativa que apresenta-se como um subsídio no enfrentamento das desigualdades pelos grupos humanos relacionados à raça, ao gênero e a orientação sexual.

É buscando enfrentar esses desafios que muitas mulheres procuram a EJA que, na concepção de SILVA (2013, p. 05), “é uma medida compensatória, passando pelas lutas populares, pela alfabetização de adultos até a conquista do direito à vivência da vida adulta como um importante ciclo de formação humana". A Educação de Jovens e adultos é uma oportunidade de inclusão para aqueles que não puderam estudar na idade certa. Na situação das mulheres, geralmente, buscam concluir os estudos para conseguir qualificação no trabalho, não ser demitida por não ter o conhecimento escolar exigido e para adentrar em um curso de nível superior.

Para Fernandes et al (2016), as mulheres procuram a EJA a fim de ter a oportunidade de conseguir um emprego digno, com uma remuneração justa e manter contato com a sociedade contemporânea, letrada e digitalizada. Estes autores concluem que a escolarização e o trabalho possuem uma relação intrínseca já que a maioria exerce 
profissão de doméstica e não tem valorização salarial, além dos preconceitos que as mesmas sofrem por estarem em uma profissão que representa, em geral, uma posição de subalternidade.

Nesse contexto, a EJA pode contribuir de maneira eficaz através do ensino na formação de mulheres conscientes dos seus direitos nas esferas econômicas, políticas e sociais, despertando um pensamento crítico e possibilitando o empoderamento das estudantes de modo a corroborar com o que Fernandes et al (2016) afirma:

a Educação de Jovens e Adultos está fazendo seu papel, isto é, está preparando mulheres com pensamentos críticos e somente seus, dando-lhes a oportunidade de serem donas de si próprias e de se postarem em lugares que são seus por direito, como a escola, trabalho e qualquer outro onde elas quiserem estar (FERNANDES et al, 2016, p. 7).

O fato de a mulher desejar e ter a oportunidade de ingressar ou de regressar para a escola na vida adulta já representa um avanço, uma vez que a mesma tem a consciência da sua capacidade de poder enfrentar os desafios e do seu potencial de aprender a ler, a escrever e de prosseguir os diversos níveis de estudo para assim conquistar seus objetivos. Mesmo a EJA cumprindo seu papel, na maioria das vezes, sabe-se que a carência de recursos nessa modalidade ainda é muito grande, por isso é importante o fortalecimento de políticas públicas voltadas para essa esfera educacional uma vez que a EJA e seus programas correspondem ao segmento educacional que mais possibilita a inserção da mulher negra (FERNANDES, et al, 2016).

De acordo com Costa (2009), a EJA é uma modalidade de ensino movida por ações populares, na perspectiva da educação para todos a partir das quais os movimentos da década de 1960 lutavam por uma educação de qualidade. Ainda conforme a autora, a educação popular passou a ser discutida não apenas pelo viés das diferenças entre as classes sociais, mas também, como práticas para a transformação da realidade social por meio da educação de modo a ser vista como uma perspectiva de mudança social no país.

Ainda salienta Costa (2009) que a modalidade de educação para adultos em 1970 era uma tentativa de reduzir o analfabetismo no Brasil, com a proposta do Movimento Brasileiro de Alfabetização (MOBRAL). O objetivo era preparar os cidadãos para a mão de obra econômica. A partir do MOBRAL “criou-se o ensino supletivo, regulamentado pela mesma legislação de 1971, que foi um marco na história 
da educação de jovens e adultos do Brasil" (COSTA 2009, p. 27). O objetivo do ensino supletivo era possibilitar uma formação em massa para atender às demandas da modernização no país e infelizmente, até os dias atuais, a EJA acontece nessa vertente da preparação para o mercado de trabalho. Contudo, as diretrizes curriculares para a EJA apresentam uma proposta de educação para o mundo do trabalho já que esta última não se limita à formação técnica, mas prioriza a formação cidadã a partir da reflexão acerca dos direitos, deveres e problemas sociais.

A luta pelo acesso à escola pública e de qualidade para as camadas populares têm uma longa trajetória, em que a proposta da educação popular assumiu significativa importância. Pode-se afirmar que ela mesma foi e ainda é impulsionadora da educação de jovens e adultos, considerando que a EJA, em sua origem, baseia-se nos princípios da educação como prática social, compreendida como um processo histórico e social (COSTA, 2009).

A modalidade de ensino EJA tem uma história política bem peculiar, com fortes interesses governamentais para o desenvolvimento econômico do país, sendo que os discentes desse modelo de ensino são das camadas populares que pretendem retomar os estudos, mas que nas últimas décadas têm forjado um caráter mais político e democrático que prioriza os interesses da classe trabalhadora, ainda que a passos lentos.

Contudo, é possível perceber certa discriminação da classe hegemônica para com a EJA, uma vez que os recursos destinados a essa modalidade de ensino é inferior às demais modalidades e torna-se insuficiente para o desenvolvimento das atividades pedagógicas mais eficazes. A portaria interministerial 07/2018 prevê R $\$ 3.562,37$ anuais por aluno nas séries finais do ensino fundamental urbano e R\$2.590,82 para a EJA. Para a EJA integrada a Educação Profissionalizante o valor é de R\$ 3.886,23 anuais na Bahia enquanto que para o aluno do ensino médio integrado a educação profissionalizante, o valor previsto é de 4.210,08 por ano (BRASIL, 2018).

Essas pessoas fazem parte de uma minoria que precisa lutar todos os dias para ter acesso aos seus direitos enquanto cidadãos e cidadãs. A sociedade que discrimina a EJA não considera os motivos pelos quais esses sujeitos não puderam concluir os estudos na idade certa, por isso defendem o Estado quando este não investe no ensino acreditando não valer todo o esforço e desacreditando da potencialidade dos estudantes em seguir até o ensino superior. 
Concordando com Costa (2009), ao falar em EJA e superação dos problemas sociais faz-se necessária a menção ao educador Paulo Freire e sua forte contribuição na sistematização do ensino na Educação de Jovens e Adultos com a inserção de temas geradores na prática educativa levando os sujeitos a conhecer, compreender o mundo a sua volta e o transformar.

Nesse sentido, faz-se necessário uma prática pedagógica voltada para esse público específico, levando em consideração o seu contexto social, seus objetivos ao retomar os estudos, bem como a sua idade. Tratando-se das mulheres negras a situação é de muita criticidade, já que a sua história é de contínuo conflito entre a subalternidade e o poder, decorrente da questão do gênero e raça onde a mulher foi considerada, ao longo da história, inferior ao homem no meio social, mas também consequência da questão racial, já que por ser negra e historicamente estar num lugar de mulher explorada sempre teve seus direitos socialmente negados.

\section{A MULHER NEGRA E OS DESAFIOS ESCOLARES NA}

\section{CONTEMPORANEIDADE}

Retomando a informação acerca da superioridade educacional em números de acesso e permanência existente entre as mulheres brancas em relação às mulheres negras Costa (2015, p. 02) afirma que "em um recorte por raça/cor e gênero (feminino), as mulheres negras ficam em disparidades com as brancas”. Isso acontece devido às desigualdades que essas mulheres precisam enfrentar no seu cotidiano, ocasionando de certa maneira a exclusão frente as mulheres brancas. Essa afirmação é referente às diversas esferas educacionais, exceto na EJA, onde a predominância é das mulheres brancas e onde as negras geralmente não tiveram acesso inicial ou continuidade deste devido à falta de oportunidade, seja porque precisou interromper os estudos para trabalhar e ajudar a família seja por outros motivos que surgem no decorrer da sua trajetória de vida.

É por isso que MARCONDES et al (2013) insiste na afirmação de que o racismo é uma ideologia que está presente nas relações profissionais, institucionais e acadêmicas, simbólica ou explicitamente, não deixando de ser agressiva às classes consideradas subalternizadas. Apesar dos avanços em relação às políticas afirmativas 
voltadas para a população negra ainda assim é possível perceber a desigualdade entre raças e gênero no cenário brasileiro.

De acordo com a Pesquisa Nacional por Amostra de Domicílios - PNAD (2017), no geral a taxa de analfabetismo é mais do que o dobro entre pretos e pardos $(9,9 \%) \mathrm{em}$ comparação aos brancos (4,2\%). No que tange as mulheres negras a realidade ainda é mais difícil, principalmente no contexto da EJA, onde muitas são chefes de família e ainda precisam estudar para o aprimoramento profissional. Segundo Marcondes et al (2013), uma pesquisa realizada em 2009 detectou que as mulheres negras recebiam em média $40 \%$ do que recebiam as brancas, acrescido do fato de que as piores condições de renda são das mulheres negras chefes de família. Pode-se afirmar ainda que essa diferença está também relacionada com o grau de escolarização, uma vez que, na maioria das vezes, a mulher negra não pôde concluir os estudos na idade regular por questões econômicas e que a valorização profissional está interligada ao nível de escolarização, além do mercado de trabalho ser um setor de muita discriminação.

As mulheres provenientes das classes mais pobres (majoritariamente negras) dirigem-se para os empregos domésticos, de prestação de serviços e também para os ligados à produção na indústria; enquanto as mulheres de classe média, devido às maiores oportunidades educacionais, dirigem-se para prestação de serviços, para áreas administrativas ou de educação e saúde. (MARCONDES et al., 2013, apud BRUSCHINI e LOMBARDI, 2000, p. 85)

Essa é a realidade das mulheres que buscam se inserir na Educação de Jovens e Adultos, sendo estas marginalizadas devido à desigualdade social a que são submetidas cotidianamente. Mesmo assim abraçam a oportunidade de continuar os estudos e fazer parte de uma sociedade escolarizada. De acordo com Souza (2012) estas tiveram suas vidas marcadas pela exclusão, pelas perdas e pelas desesperanças, mas anseiam pela ampliação de seus conhecimentos.

Nesta perspectiva, Souza (2008, p. 01) afirma que o "número de mulheres negras matriculadas na EJA é significativo em relação ao restante das alunas de cor parda ou branca". Essa expressiva presença de mulheres negras na EJA como fruto de uma história marcada pela discriminação revela a necessidade de uma prática pedagógica voltada para a realidade desse público que busca essa modalidade de ensino para se inserir numa sociedade escolarizada e assim atingir seus objetivos principalmente no mundo do trabalho formal. 
Ainda segundo Souza (2008) para as estudantes negras em processo de alfabetização, matriculada na EJA, aprender a ler e a escrever é um desafio desmesurado, se as ações não forem motivadoras e inovadoras na leitura e na escrita pois "é assim que a educação poderá gerar conhecimento disponibilizado de forma assertiva para a humanidade" (CYNTHIA ROSENBURG, 2002 p. 28 apud SOUZA, 2008, p. 03).

$\mathrm{Na}$ vertente simultânea da leitura e do letramento significativo na vida dessas mulheres é possível a inclusão das mesmas no meio social no qual foram excluídas por tantos anos. Nesta direção, Souza (2008) traz a proposta do letramento digital salientando a importância de se apresentar essa novidade enquanto diferente e provocante. $\mathrm{O}$ interessante dessa prática é a contextualização, uma vez que no cotidiano essas mulheres estão cercadas por esses instrumentos digitais no trabalho, em agências bancárias, com o uso do celular, dentre outras atividades, daí a importância do uso dos computadores e celulares nas aulas para os alunos da EJA.

Sabe-se que praticar o letramento digital em sala de aula é um desafio e que isso também depende de recursos e investimentos por parte do Estado, como disponibilidade de aparelhos tecnológicos e formação continuada adequada do profisssional de educação atuante na EJA, mas é possível. Para tanto é importante que o Estado, através do educador tenha um olhar crítico sobre a realidade dos alunos para que as práticas pedagógicas favoreçam a aprendizagem dos educandos, incluam o letramento digital, respeite a experiência de vida e a realidade cultural dos sujeitos, ajude-os a adquirir novos saberes que redefinam o seu conhecimento.

\section{A REALIDADE DE UMA ESCOLA COM OFERTA DE EJA}

De acordo com os dados do INEP no Censo Escolar de 2018 o número de pessoas do sexo feminino com defasagem de idade em relação à etapa que cursam é menor do que a do sexo masculino em todas as etapas de ensino e a maior diferença é observada no ensino fundamental. Foi possível observar também no censo escolar nacional de 2018 que 60,7\% das matrículas na EJA são de mulheres. Comparando com o total de alunos das turmas da escola analisada no município de Ilhéus, foi possível observar que o número de matrícula de mulheres superou o número de homens o que 
implica dizer que as mulheres têm buscado mais e acreditado mais na EJA como caminho viável para dar continuidade aos estudos.

No que compete à cor dos educandos da EJA nesta instituição, questão central desta pesquisa, observa-se que a maioria é da cor negra, como pode ser visto nos gráficos I e II, III e IV.

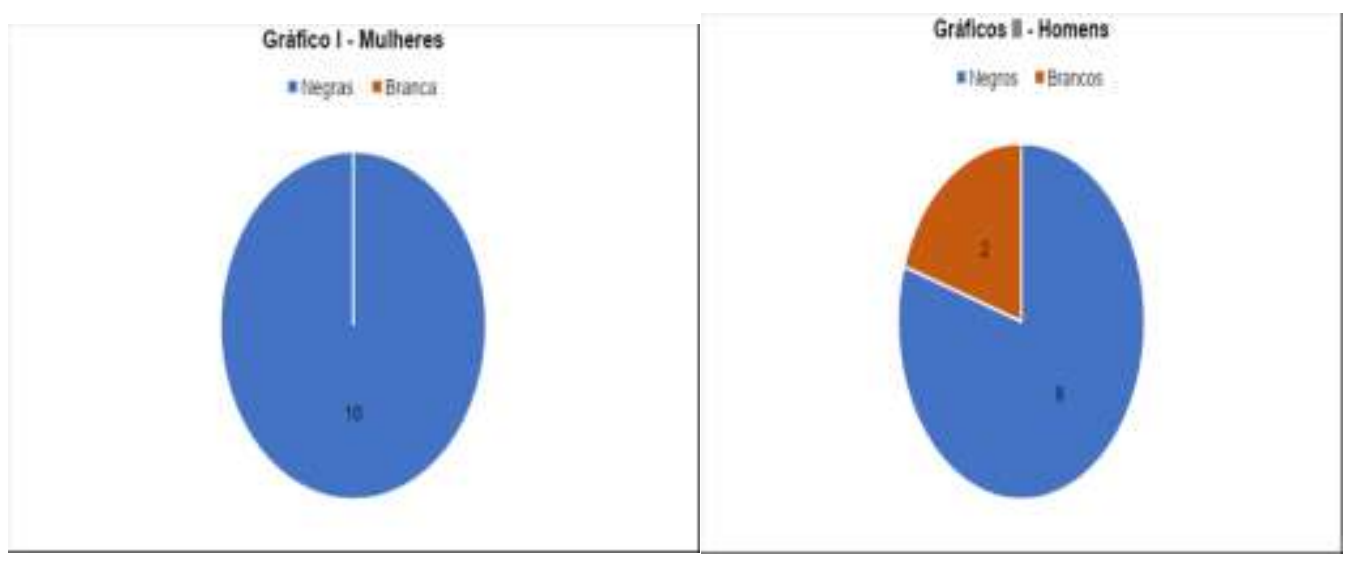

A turma I era composta por dez mulheres, todas autodeclaradas negras. Já dentre os homens oito eram autodeclarados negros nas fichas de matrículas e dois brancos. Esses dados confirmam a discussão de Fernandes et al (2016) de que a modalidade EJA é mais frequentada por negros em relação às demais etnias que compõem a população geral do Brasil. Vale aqui ressaltar que considerou-se negros e negras todas e todos os estudantes que na ficha de matrículas se autodeclararam da cor preta ou parda seguindo assim o critério de classificação utilizado pelo Instituto Brasileiro de Geografia e Estatística - IBGE. ${ }^{4}$

Quando se analisou o estado civil das estudantes, seis estão sinalizadas como casadas e quatro solteiras, sendo que das casadas todas trabalham: três como domésticas, duas como vendedoras e uma como autônoma. Das quatro estudantes solteiras três não trabalham e a que constava como trabalhadora não informou a profissão.

4 Reconhecemos que o termo pardo não é exclusividade da mistura étnica do negro com o branco. Ela pode incluir a relação branco/indígena, negro/indígena e indígena não aldeado, contudo, não faremos essa discussão neste texto. É possível aprofundar o assunto no artigo científico Pardos, mestiços ou caboclos: os índios nos censos nacionais no Brasil (1872-1980) de João Pacheco de Oliveira, dentre outros estudos. 
Na turma II também foi possível constatar que a maioria dos educandos possui a etnicidade negra e esse fenômeno pode ser observado nos gráficos III e IV.

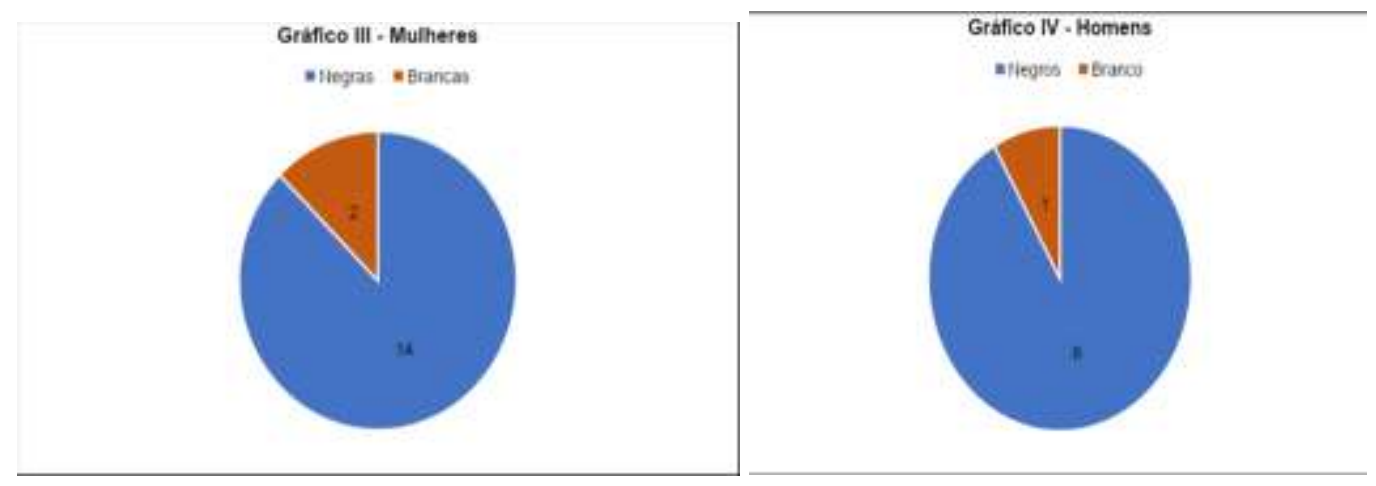

No que se referem às dezesseis mulheres, quatorze são negras e duas pertencem à cor branca. Entre os doze estudantes do sexo masculino, onze são negros e apenas um é da cor branca. No tocante ao estado civil das discentes, nove são casadas e todas exercem profissões fora de casa, sendo cinco como domésticas. Já em relação às mulheres solteiras apenas quatro trabalhavam fora de casa e as profissões foram informadas nas fichas de matrículas como "outros". Três destas estudantes disseram que não trabalhavam.

A turma I é composta por vinte estudantes, sendo dez do sexo feminino e dez do sexo masculino. De acordo com o mapa final de avaliação da turma, das dez mulheres matriculadas quatro evadiram, três foram aprovadas e três conservadas ${ }^{5}$. De acordo com os dados é possível perceber que a quantidade de pessoas do sexo masculino que evadiu (cinco) é maior que do sexo feminino (quatro). O número de aprovados foi igual e houve um número maior de mulheres conservadas no mesmo eixo formativo. Assim pode-se concluir que apesar das dificuldades que as mulheres enfrentam no cotidiano, ainda são a maioria na sala de aula da EJA nesta turma conforme ilustrado nos gráficos V e VI.

5 Os termos conservadas e reprovadas são sinônimos e a opção pelo termo conservadas segue a terminologia utilizada nos documentos analisados durante a pesquisa e representam uma opção política de que o estudante conservado apenas não atingiu a meta estabelecida já que certamente ocorreu aprendizagem durante o ano letivo. 


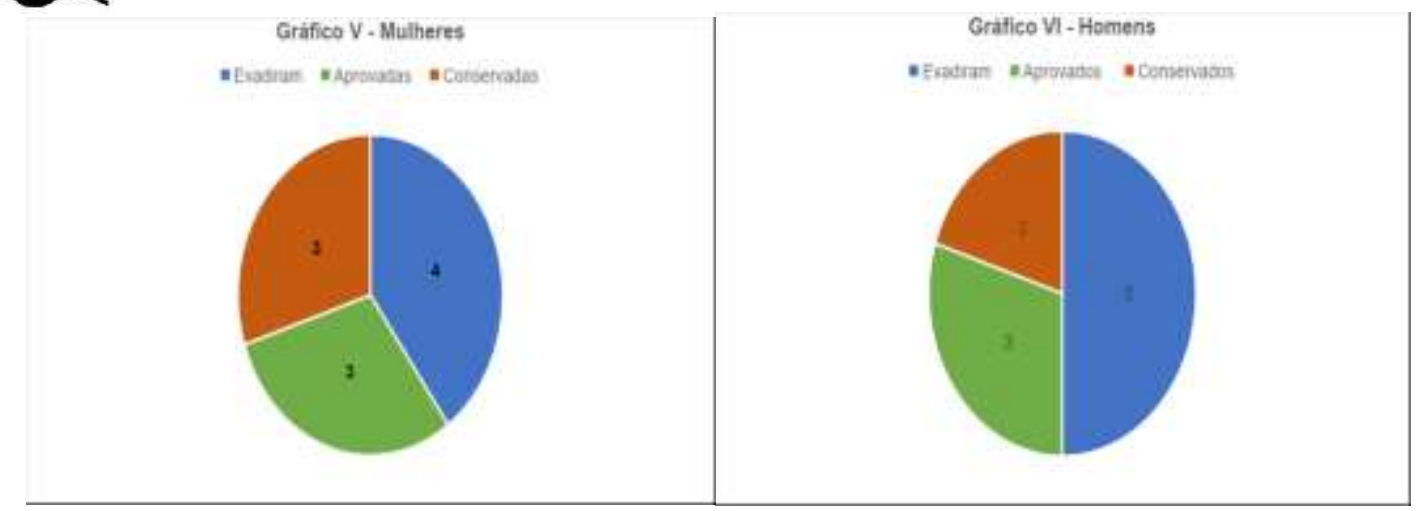

Segundo Fernandes et al (2016), nessa modalidade de ensino muitas mulheres deixam de frequentar a escola para cuidar da família, seguindo o modelo patriarcal, onde a obrigação de cuidar dos filhos e afazeres domésticos são "socialmente" delegados a mãe. Essa situação geralmente acontece com as mulheres casadas, onde os pais trabalham para a manutenção da família e as mães cuidam da casa. Quando se trata de mulheres consideradas chefes de família a situação é diferente, pois estas além de administrar o lar ainda precisam trabalhar para garantir o sustento da família.

A partir da análise do mapa da turma II ilustrado nos gráficos abaixo é possível observar o que:

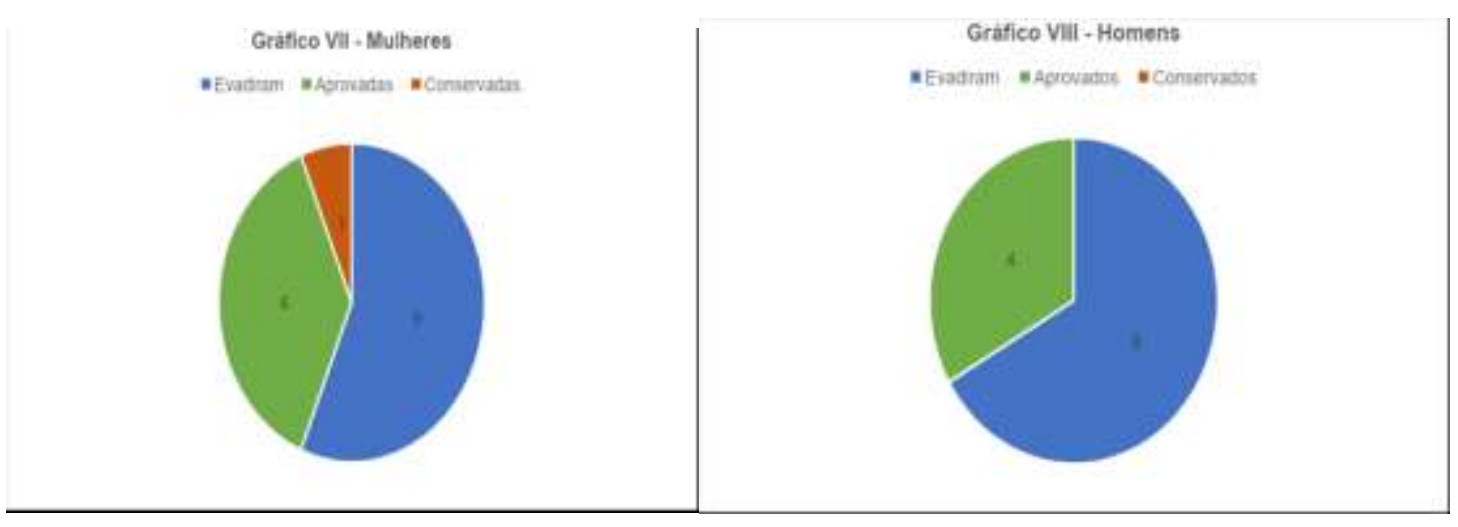

Inicialmente essa turma II era composta por vinte e oito estudantes dos quais dezesseis eram mulheres, mas no decorrer do ano, nove delas evadiram. Ao final do ano seis foram aprovadas e uma conservada. Também foi possível perceber que para todas as mulheres que evadiram constava na ficha de matrícula a informação de que elas têm filhos. Nesse sentido, Fernandes et al (2016) afirma que há dificuldades que impedem as mulheres de permanecer na escola e cita a sobrecarga das funções diversas que elas 
precisam exercer, uma vez que são responsáveis por cuidar da casa, dos filhos, trabalhar fora de casa para ajudar ou para garantir o sustento da família e estudar.

No que concerne ao sexo masculino, de acordo com o mapa de avaliação final, foi possível afirmar que na turma II foram matriculados doze homens, dos quais oito evadiram no decorrer do ano letivo e quatro foram aprovados. Para Fernandes et al (2016), no PNAD de 2009, o público da EJA no geral apresentava-se de forma equilibrada entre homens e mulheres, porém havia $10 \%$ a mais de mulheres que efetivamente frequentavam a EJA. Também se observou que a evasão masculina superou a feminina na turma I enquanto que na turma II houve uma inversão no índice de evasão ( 9 mulheres e 8 homens).

Apesar de todas as dificuldades que as mulheres enfrentam para continuar os estudos, os números de evasão dos homens (13) e das mulheres (13) destas duas turmas ficaram equiparados quando faz-se a junção dos números $(20+28=48$ alunos). Portanto, é preciso pensar e realizar um fazer pedagógico para a EJA considerando todos esses desafios postos até aqui para esse público, em especial para as mulheres, de tal maneira a serem criadas ou implementadas políticas públicas capazes de favorecer a continuidade dos discentes nos estudos, reduzindo assim o alto índice de evasão até então observado.

Nesse sentido, Paulo Freire (2001) diz que a Educação de Jovens e Adultos pode ser percebida como Educação Popular, exigindo assim a compreensão crítica dos educadores em relação a prática pedagógica que precisa abordar assuntos do cotidiano dos estudantes: "O que acontece, no meio popular, nas periferias das cidades, nada pode escapar a curiosidade arguta dos educadores envolvidos na prática da Educação Popular" (FREIRE 2001, p. 16). Nesse contexto, o saber dos educandos não pode ser desprezado em sala de aula, ao contrário, deve ser um ponto de partida na prática do professor que, com os estudantes, pode estabelecer como meta de aprendizagem a compreensão dos conteúdos acadêmicos a partir de e associada a uma análise crítica da realidade social, superando assim, o senso comum.

Nessa vertente a escola pode se tornar até mais atrativa e interessante para os estudantes da EJA uma vez que eles têm a oportunidade de colocar em prática a sua experiência, com "palavras geradoras", superando assim o senso comum e buscando fazer uma leitura crítica do mundo ao seu redor e "não aceitando assim, a posição de 
neutralidade política com que a ideologia modernizante reconhece ou entende a Educação de Adultos" (FREIRE, 2001 p. 16).

Nessa perspectiva, para atender a esse público e cumprir a sua função é relevante que os profissionais envolvidos na EJA considerem as especificidades dos estudantes, principalmente das mulheres no geral, já que culturalmente estas já são tão discriminadas no meio social onde:

A questão da identidade cultural, de que fazem parte a dimensão individual e a de classe dos educandos cujo respeito é absolutamente fundamental na prática educativa progressista, é problema que não pode ser desprezado (FREIRE, 1996, p. 19).

A prática pedagógica caminhando por esta vertente possibilita a sensibilização das educandas e dos educandos para que os mesmos adquiram instrumentos de luta contra os obstáculos da vida social e política que enfrentam no seu cotidiano e passem a ocupar a posição de sujeitos ativos numa sociedade que ainda apresenta características de extrema desigualdade. Portanto,

A escola constitui espaço para repensar o currículo e alterá-lo dentro das demandas e legislações em vigência no campo da educação e, em função disso, tensões se desenrolam e tomam corpo [...] Nesta perspectiva, persistir na defesa de que a escola é plural sem visibilizar as práticas dos grupos sociais e raciais que a compõem significa colaborar com a perpetuação da invisibilidade e exclusão de afrodescendentes. Pensar no ambiente escolar enquanto espaço respeitoso demanda questionar o postulado de uma cultura europeia universal, ponto de comparação e hierarquização para demais grupos e sujeitos (SANTOS, 2018, p. 841).

É preponderante sinalizar ainda que sendo abordadas questões de valorização dos educandos da EJA, principalmente das mulheres negras, possibilita-se $\mathrm{o}$ desenvolvimento da atuação crítica no mundo do trabalho para que haja de fato o empoderamento por parte das mesmas no meio social decorrente da oferta e da vivência de um ensino de qualidade que contribua com a formação humana desses sujeitos.

\section{CONCLUSÃO}

De acordo com a pesquisa realizada nesta escola, a entrada de homens e mulheres na turma I foi à mesma, mas a permanência das mulheres superou a dos 
homens, apesar do sucesso dos homens na aprovação ter sido maior. Já na turma II a entrada de mulheres foi maior, porém a permanência e o êxito dos homens foram superiores em relação às mulheres. Apesar das dificuldades que as mulheres enfrentam no cotidiano desempenhando papéis enquanto donas e chefes de casa, profissionais e mães, elas persistem em estudar e o alto índice de reprovação e evasão pode ser devido à dificuldade em se dedicar mais aos estudos devido a essas atividades que elas precisam conciliar com o processo de escolarização haja vista a predominância de uma cultura machista que impede a divisão equânime das tarefas e responsabilidades domésticas.

Diante desta constatação, pode-se afirmar que seria importante a implementação de políticas públicas com o objetivo de reparar a evasão e a conservação/reprovação na EJA. Dentre as ações que devem permear a implementação destas políticas está a criação de creches no período da noite, programas de incentivos a continuidade dos estudos, projetos atrativos para os estudantes em geral, prática pedagógica específica para o público da EJA e a valorização de todos os envolvidos nesta modalidade de ensino.

No que concerne à cor dos estudantes, é possível afirmar que a maioria dos estudantes, tanto homens quanto mulheres são negros e negras. Tratando-se da perspectiva de gênero, o número de mulheres negras é maior do que os homens. Assim, essas mulheres, por enfrentar dificuldades cotidianamente em decorrência de várias razões sociais, políticas e econômicas não conseguiram concluir os estudos na idade considerada certa e procuram a modalidade de ensino EJA o que resulta em um público que apresenta suas peculiaridades, sendo educandos diferenciados por já possuírem suas experiências mais amadurecidas frente aos alunos do ensino fundamental ou médio regular.

Tratando-se especificamente da mulher negra no cenário brasileiro foi possível identificar a história de discriminação que essas vem sofrendo ao longo dos séculos. Como resultado da luta dos movimentos negros houve avanço em algumas políticas públicas sociais e educacionais visando reparar os anos de escravização e discriminação do povo negro dentre eles as mulheres negras. Ainda assim é possível perceber que os conceitos de gênero construídos historicamente atingem diretamente a vida das mulheres negras as quais enfrentam simultaneamente a discriminação de gênero e de 
cor/etnia, por isso ainda há muito o que lutar para que estas sejam reconhecidas, respeitadas e usufruam com equidade os seus direitos sociais.

\section{REFERÊNCIAS}

ALMEIDA, Maria Izabel de. Docentes para uma educação de qualidade: uma questão de desenvolvimento profissional. In revista Educar, Curitiba, n. 24, p. 165-176. 2004. Editora UFPR.

BAHIA. Secretaria da Educação. Manual de Programação Escolar - Regras 2018. Disponívelem: escolas.educacao.ba.gov.br. Acesso em: 17/12/2019.

BARDIN, Laurence. Análise de conteúdo. Portugal: Edições Loyola, 2010.

BRASIL. Instituto Brasileiro de Geografia e Estatística. PNAD. Brasília DF 2017. Disponível em: www.ibge.gov.br . Acesso em: 12/09/2018.

BRASIL. Ministério da Educação. Censo Escolar 2018. INEP. Brasília DF-Fevereiro 2017.

BRASIL. Portaria interministerial $\mathrm{n}^{\mathrm{o}} 7$, de 28 de dezembro de 2018. Disponível em: www.in.gov.br . Acesso em: 05/06/219.

BRASIL. Presidência da República Casa Civil. LEI N 12.288, DE 20 DE JULHO DE 2010. Estatuto da Igualdade Racial. Brasília, 20 de julho de 2010; $189^{\circ}$ da Independência e $122^{\mathrm{a}}$ da República.

COSTA, Gracyelle Silva. Trajetória de escolarização de jovens negras no ensino médio. $37^{\mathrm{a}}$ Reunião Nacional da ANPEd - 04 a 08 de outubro de 2015, UFSC - Florianópolis.

COSTA, Rosenilda Trindade da. Jovens negras em processo de escolarização na EJA. Dissertação (mestrado) - Universidade Católica de Goiás, Departamento de Educação, 2009.

SANTOS, Carina Santiago dos. A educação de jovens e adultos na rede municipal de florianópolis: do funcionamento à elaboração de material para o ensino de história e cultura africana e afro-brasileira. Revista da Associação Brasileira de Pesquisadores/as Negros/as (ABPN), [S.1.], v. 10, n. Ed. Especi, p. 836-847, jun. 2018. ISSN 2177-2770. Disponível em: $<$ http://abpnrevista.org.br/revista/index.php/revistaabpn1/article/view/483>. Acesso em: 21 out. 2019.

FERNANDES, Caroline Lins et al. (Orgs). A inserção da mulher na modalidade eja. Departamento de Química, Universidade Estadual da Paraíba-UEPB, Campus I, Campina Grande-PB, 2016.

FREIRE, Paulo. Pedagogia da autonomia: saberes necessários à prática educativa. São Paulo, Paz e Terra, 1996.

FREIRE, Paulo. Política e Educação. São Paulo, Cortez, 1997.

MARCONDES, Mariana et al. (Orgs.). Dossiê mulheres negras: retrato das condições de vida das mulheres no Brasil. Brasília: Ipea, 2013. 
MUNANGA, Kabengele e GOMES, Nilma Lino. Para entender o negro no Brasil de hoje: histórias, realidades, problemas e caminhos. São Paulo: Ação Educativa, 2006.

NASCIMENTO, Francineide Bárbara Silveira do Nascimento e SANTOS, Jocenildes Zacarias. Mulher negra e EJA: estratégias de enfrentamento à violência na escola. Revista Cenas Educacionais, Caetité - Bahia - Brasil, v. 1, n. 1, p. 70-90, jan./jun. 2018.

NUNES, Georgina Helena Limaetal (Orgs). Diversidade e inclusão. Pós graduação a distância. São Leopoldo RS, 2018.

PEREIRA, Fábio Batista. PÓS-ABOLIÇÃO. Liberdade e Cidadania Educação de Jovens e Adultos - Tempo Formativo III. Mestrado Profissional em História da África, da Diáspora e dos Povos Indígenas. Universidade Federal do Recôncavo da Bahia, 2015.

RIBEIRO, Vera Masagão, CATELLI, Roberto Jr, HADDAD, Sérgio (Org.) A avaliação da eja no Brasil: insumos, processos, resultados. Núcleo de Estudos Educação de Jovens e Adultos Brasília: Instituto Nacional de Estudos e Pesquisas Educacionais Anísio Teixeira, 2015. (Série Documental. Relatos de Pesquisa, ISSN 0140-6551;).

SILVA, Natalino Neves da. A(in)visibilidade da juventude negra na EJA: percepções do sentimento fora do lugar. 36 ${ }^{\mathbf{a}}$ Reunião Nacional da ANPED - 29 de setembro a 02 de outubro de 2013, Goiânia-GO.

SILVA, Sá Jackson Ronies, ALMEIDA, Domingos Cristovam de GUINDANI, Joel Felipe. Pesquisa Documental: pistas teóricas e metodológicas. Revista Brasileira de História e Ciências Sociais. Ano I - Número I - Julho de 2009. ISSN: 2175 - 3423.

SOUZA, Celina. Políticas Públicas: uma revisão da literatura. In: Revista Sociologias, Porto Alegre, ano 8, no 16, jul/dez 2006, p. 20-45.

SOUZA, Maria Antônia de. Educação de Jovens e Adultos. Curitiba: Editora Inter Saberes, 2012.

SOUZA, Neuza Maria Câmara de. A inclusão digital da mulher negra nas turmas da EJA de Santa Cruz de Minas: superando a exclusão social. Web Artigos. Nov. de 2008. Disponível em: https://www.webartigos.com/artigos/a-inclusao-digital-da-mulher-negra-nas-turmas-da-eja-desanta-cruz-de-minas-superando-a-exclusao-social/11886. Acesso em:17/02/19.

Recebido 30/11/2019

Aprovado em: 30/01/2020 